\title{
Gastric cancer in young people under 30 years of age: worse prognosis, or delay in diagnosis?
}

\author{
This article was published in the following Dove Press journal: \\ Cancer Management and Research \\ 3 April 2013 \\ Number of times this article has been viewed
}

\author{
Horacio Noé López-Basave' \\ Flavia Morales-Vásquez ${ }^{2}$ \\ Juan Manuel Ruiz-Molina' \\ Silvio A Ñamendys-Silva ${ }^{2}$ \\ Itzel Vela-Sarmiento' \\ Javier Melchor Ruan' \\ Alejandro E Padilla Rosciano' \\ German Calderillo-Ruiz ${ }^{2}$ \\ Consuelo Díaz-Romero ${ }^{2}$ \\ Angel Herrera-Gómez' \\ Abelardo A Meneses- \\ García $^{3}$ \\ 'Departamento de Cirugía \\ Oncológica, ${ }^{2}$ Departamento de \\ Oncología Médica, ${ }^{3}$ Departamento de \\ Terapia Intensiva, Instituto Nacional \\ de Cancerología (INCan), Mexico \\ City, Mexico
}

Correspondence: Horacio Noé LópezBasave

Departamento de Cirugía Oncológica, Instituto Nacional de Cancerología, Av San Fernando \#22, Col Sección XVI, Tlalpan, México, DF, México Email lobohnoe@gmail.com
Background: Gastric cancer is an aggressive disease with nonspecific early symptoms. Its incidence and prognosis in young patients has shown considerable variability.

Purpose of the study: Our objective was to retrospectively study patients from our institution aged $<30$ years with gastric carcinoma. The study was undertaken to describe the experience of gastric cancer in this population, and to demonstrate its specific clinical and pathological characteristics.

Materials and methods: We reviewed the cases of histologically confirmed gastric cancer between 1985 and 2006 at the Instituto Nacional de Cancerología of Mexico (INCan); emphasis in our review was placed on clinical presentation, diagnostic and therapeutic intervention, pathology, and the results.

Results: Thirty cases of gastric carcinoma were reviewed. The patients' median age was 27 years (range, 18-30 years) and the male:female ratio was 1:1.

Conclusion: Gastric cancer exhibits different behavior in patients aged $<30$ years, but delay in diagnosis and the tumor's behavior appear to be the most important factors in prognosis of the disease.

Keywords: gastric carcinoma, young people, delay in diagnosis

\section{Introduction}

The incidence of gastric cancer varies widely depending on the geographic region analyzed; it has been shown to be as high as 80-82 per 100,000 inhabitants in some cities in Japan; has an intermediate incidence in Costa Rica, São Paulo, Brazil, and Cali, Colombia $(50 \times 100,000$ inhabitants $)$; and has a low incidence in Kuwait, Los Angeles, CA, USA, and Mexico $(<10 \times 100,000$ inhabitants $) .{ }^{1}$

In Latin America, the incidence of gastric cancer varies by region. Several countries, such as Chile $(46.1 \times 100,000$ inhabitants $)$, Costa Rica $(41.2 \times 100,000$ inhabitants $)$, Ecuador $(37.8 \times 100,000$ inhabitants $)$, and Peru $(37.5 \times 100,000$ inhabitants $)$ have a high rate, while other countries, such as Paraguay $(19.5 \times 100,000$ inhabitants $)$, Argentina $(14.6 \times 100,000$ inhabitants $)$, and Mexico $(13.1 \times 100,000$ inhabitants $)$, have much lower rates. ${ }^{2,3}$

In Mexico, according to the official Histopathological Registry of Neoplasms, gastric cancer is the fifth-most prevalent form of cancer in the general population (3.4\%), with a calculated incidence rate of 10.9 per 100,000 inhabitants. Types of cancer that are more common in Mexico are cancer of the uterine cervix, skin cancer (nonmelanoma), breast cancer, and prostate cancer (which is the most common form of cancer in the country). 
Gastric cancer is the second-leading cause of death from cancer in Mexico, and the most common cause of death from gastrointestinal cancer. In general, Mexico is considered a lowrisk area, with a mortality rate of 5.0 per 100,000 inhabitants, ${ }^{3}$ with great geographic variability within the country. The state of Chiapas has the highest mortality rate (6.4 per 100,000$)$; the Federal District comprising Mexico City and surroundings has a rate of 4.5 per 100,000 inhabitants, and the State of Mexico, has a rate of 2.5 per 100,000. Men are affected more frequently than women at a ratio of $1.5: 1-2: 1{ }^{4}$

In Mexico, gastric cancer has been most frequently observed in persons aged between 50 and 70 years; however, $<10 \%$ of cases are detected prior to the age of 45 years. $^{5}$ The proportion of young patients with gastric adenocarcinoma has varied from $6 \%-8 \%$ in studies in which patients were defined as young when aged $<41$ years and from $2 \%-6 \%$ in studies in which young patients were defined as being $<36$ years of age. In these younger population subsets, epidemiological differences exist in localization, with an increase of lesions at the proximal level as well as in those in the antral region. Lesions at the proximal level have been most often experienced by those whose race can be characterized as white (71\% vs 29\%), while antral lesions were predominant in those who were characterized as black (64\% vs 36\%). ${ }^{6}$ With respect to clinical and pathological characteristics among people aged $<30$ years compared with those 30-39 years of age, both groups exhibited similar symptoms, undifferentiated neoplasms, and poor prognosis. A delay in diagnosis existed in both groups and exerted influence on patient management and prognosis. ${ }^{7-11}$

In patients with a familial history of gastric cancer, with symptoms of ulcer that do not improve with adequate medical management, or who have received a diagnosis of an ulcer, panendoscopy should be performed, with a biopsy for early diagnosis. ${ }^{12}$ The majority of young patients come in for an appointment with a long disease history and with advanced disease. ${ }^{13}$

The Instituto Nacional de Cancerología de México (INCan) is a cancer center that cares for 3,985 patients with cancer per year. Gastric cancer represents 3.7\% of neoplasms seen at the institute, with 150 cases of gastric cancer reported annually. Our study attempts to retrospectively evaluate the general characteristics and behavior of gastric cancer in patients $<30$ years of age seen at this Institution.

\section{Patients and methods}

At the INCan's Surgery Department, we carried out a review of cases of patients aged $<30$ years who had received a diagnosis of gastric cancer between January 1985 and January 2006. From this search, we identified a total of 2153 cases, among which only 30 were corroborated in patients aged $<30$ years. This group was eligible for this retrospective analysis.

For each case, we included age, gender, familial oncological history, signs and symptoms referred, types of preparatory studies performed, and methods utilized for diagnosis; in addition, we considered follow-up time and time lapse to death or date of last medical appointment. Overall survival (OS) time was considered, as were the date of specific treatment initiation, whether the patient died (due to any cause), and date of last medical appointment.

We only employed descriptive statistical methods in statistical analysis with central tendency and dispersion measurements. Survival curves were estimated using the Kaplan-Meier method, and the log-rank test was utilized to compare survival data. In all cases, a two-tailed value of $P<0.05$ was considered statistically significant. We employed the SPPS (v 19.0 IBM Corporation, Armonk, NY, USA) for Windows software package for statistical analysis.

\section{Results}

We reported on 30 patients aged $<30$ years, with an age range of 18-30 years. The patient cohort included 16 males and 14 females; $33 \%$ of the population had oncological histories, including four cases of cervical uterine cancer, three cases of leukemia, and one case each of breast cancer, gall bladder cancer, and colon cancer. Among the other important patient characteristics, $44 \%$ had a report of signet ring cell adenocarcinoma; $70 \%$ indicated that pain was the primary manifestation of a disorder; $83 \%$ were diagnosed by endoscopy; $56.6 \%$ had been submitted to computerized axial tomography (CAT) as the auxiliary diagnostic method; and $40 \%$ of patients had been managed outside of our institution using a variety of therapeutic regimens (see Table 1); thus, only

Table I General characteristics of the patient population

\begin{tabular}{ll}
\hline Age, years (range) & $27($ I $8-30)$ \\
Gender & \\
$\quad$ Male, n (\%) & $16(54)$ \\
$\quad$ Female, n (\%) & $14(46)$ \\
Oncological history & $33 \%$ \\
Primary manifestation & $70 \%$ \\
Endoscopy & $83 \%$ \\
Tomography & $57 \%$ \\
Previous management & $40 \%$ \\
Clinical stage & \\
IIIC & $5(I 7 \%)$ \\
IV & $25(83 \%)$ \\
\hline
\end{tabular}


$56.6 \%$ of patients were candidates for management at our institution. Of this group, only 40\% (12 patients) were scheduled to undergo surgery (see Table 2). Of these, $42 \%$ (five patients) qualified for tumor resection, an additional five $(42 \%)$ were submitted to gastrojejunal anastomosis-type derivations, and two (16\%) were submitted to exploratory procedures (one laparoscopy and one laparotomy). The procedures performed are described in Table 3 .

The predominant histology found was signet ring cell adenocarcinoma, in 13 patients (44\%). Twenty-five patients $(83 \%)$ were diagnosed with clinical stage IV disease, and five (17\%) with clinical stage III disease (see Table 4). With respect to symptoms, $70 \%$ (21 patients) presented with pain, and 3 patients each $(10 \%)$ presented with a clinical profile of gastric obstruction or early gastric fullness (see Table 5); duration from symptom initiation to disease diagnosis was 6-12 months in $80 \%$ of cases, and $1-2$ years in $10 \%$ of cases (see Table 6). Average follow-up was 5 months (range, 1 day to 26 months). It is noteworthy that only four (13\%) patients had a 1-year follow-up; $15(50 \%)$ patients had a $<1$ month follow-up period, and 11 (37\%) patients had a follow-up period of between 2 months and $<1$ year. The median follow-up was 86.8 days (see Figure 1).

\section{Discussion}

The clinical and pathological characteristics of gastric cancer diagnosed in young patients have been described in various recently published reports. In a population that included patients who were over and under the age of 30 years, Bedikian et al reported that both groups presented with similar symptoms, predominantly undifferentiated neoplasms, and poor prognosis. ${ }^{8}$ In 51 patients aged $<45$ years, these authors observed that this cancer was more frequent in females ( $57 \%$ vs $36.3 \%$ ), with the most common cancer type being diffuse (according to the Lauren classification). Lymphatic invasion presented with greatest frequency (59\% vs 38.9\%) and with greatest frequency in stage IV at diagnosis (49\% vs $35.7 \%$ ); notwithstanding this, no difference was observed in

Table 2 Treatment employed in the population studied

\begin{tabular}{lll}
\hline Characteristics & $\begin{array}{l}\text { Medical } \\
\text { treatment }\end{array}$ & $\begin{array}{l}\text { Surgical } \\
\text { treatment }\end{array}$ \\
\cline { 2 - 3 } & $\mathbf{n = 1 8 ( 6 0 \% )}$ & $\mathbf{n}=\mathbf{I 2 ( 4 0 \% )}$ \\
\hline $\begin{array}{l}\text { Gender } \\
\text { Male, } n(\%)\end{array}$ & $14(47)$ & $4(13)$ \\
Female, $n(\%)$ & $4(13)$ & $8(27)$ \\
Age, years & & \\
$<20$ & $2(7)$ & $0(0)$ \\
$>20$ & $22(73)$ & $6(20)$ \\
\hline
\end{tabular}

Table 3 Different types of surgical treatment

\begin{tabular}{llll}
\hline Treatment type & Males, & $\begin{array}{l}\text { Females, } \\
\text { n }\end{array}$ & $\begin{array}{l}\text { Total treatments, } \\
\mathbf{n}\end{array}$ \\
\hline Surgical & 4 & 8 & 12 \\
Gastrojejunal & 2 & 3 & 5 \\
anastomosis & & & \\
(derivation) & & & \\
Subtotal gastrectomy & $\mathrm{I}$ & 2 & 3 \\
Total gastrectomy & 0 & 2 & 2 \\
Other & $\mathrm{I}$ & $\mathrm{I}$ & 2 \\
\hline
\end{tabular}

5- to 10-year survival rates between young patients and those aged $>45$ years. $^{8}$

In a retrospective analysis of 72 cases of patients aged $<40$ years compared with 51 cases of patients above 70 years of age, Park et al showed that at the time of diagnosis young patients had a greater frequency of muscular layer invasion (65.3\% vs 39.2\%) without differences in survival. ${ }^{15}$ On the other hand, alterations have been studied in cell signaling pathways that can induce the genesis of gastric cancer, hereditary or not, and among these we find mutations in CDH1. It is thought that fewer than $10 \%$ of patients who develop gastric cancer with signet ring cells do so prior to the age of 45 years (in our series, this was $44 \%$ ), and that, if they do so, their genetic information is different from that which leads to sporadic carcinomas at an older age.

Additionally, the role of environmental carcinogenic factors in carcinogenesis is presumably less prominent in young people than is the genetic one; thus, hereditary gastric cancer and early-onset gastric cancer can aid in the study of carcinogenesis at this age. In our series, $33 \%$ had familial oncological histories without formation of hereditary or familial cancer, suggesting a genetic transmission component because the most frequently found types of cancer were cervical uterine cancer and leukemia. ${ }^{11,12}$ Gastrointestinal adenocarcinomas of the esophagus, stomach, and colon exhibit distinct patterns of genomic instability and oncogenesis. Focal amplifications were substantially more prevalent in gastric/esophageal adenocarcinomas than

Table 4 Gastric cancer lesion/tumor types (histology)

\begin{tabular}{|c|c|c|c|}
\hline Histological type & $\begin{array}{l}\text { Males, } \\
\mathbf{n}\end{array}$ & $\begin{array}{l}\text { Females, } \\
\mathbf{n}\end{array}$ & $\begin{array}{l}\text { Total } \\
(\%)\end{array}$ \\
\hline $\begin{array}{l}\text { Signet ring cell } \\
\text { adenocarcinoma }\end{array}$ & 5 & 8 & 44 \\
\hline $\begin{array}{l}\text { Moderately differentiated } \\
\text { adenocarcinoma }\end{array}$ & 3 & I & 13 \\
\hline $\begin{array}{l}\text { Poorly differentiated } \\
\text { adenocarcinoma }\end{array}$ & 5 & 2 & 23 \\
\hline Other histologies & 4 & 2 & 20 \\
\hline
\end{tabular}


Table 5 Prevalence of symptoms related to gastric cancer

\begin{tabular}{ll}
\hline Symptoms & Patients, \\
& $\mathbf{n}(\%)$ \\
\hline Epigastric pain & $21(70)$ \\
Obstruction & $3(10)$ \\
Early fullness & $3(10)$ \\
General symptoms (asthenia, adynamia, hyporexia) & $2(7)$ \\
Upper digestive tract bleeding & $1(3)$ \\
\hline
\end{tabular}

in colorectal tumors. These genomic amplifications act as biomarkers to guide therapy. ${ }^{14-16}$

It is thought that gastric cancer results from a combination of environmental factors and an accumulation of specific genetic alterations, due to the fact that the growing genetic instability mainly affects older patients, as different $p 53$ alterations in different events of gastric carcinogenesis have demonstrated. ${ }^{17}$

Rugge et al related gastric epithelial dysplasia (GED) with the development of cancer, concluding that in GED 1 with atrophic gastritis in older patients and in GED 2 strict follow-up must be conducted. Surgical management is justified for GED 3. ${ }^{18}$

There is a tendency of late diagnosis of the disease in young patients. Physicians should have a high suspicion of the disease in patients with a familial history of gastric cancer, with ulcer symptoms that do not improve with adequate medical management, or when an ulcer is diagnosed. In addition, panendoscopy should be inevitably carried out with a biopsy for early diagnosis, which can increase the survival of young patients; the latter can increase with knowledge of the patient's familial history, such as the existence of carriers of pernicious anemia, and of their first-degree relatives, in whom progression of atrophic gastritis is 20 times more rapid than in general population. ${ }^{19,20}$

Tumor staging directly affects treatment options and survival; in many cases, we encountered unstaged disease, although not in all patients. Also, there are differential staging levels for age, gender, race, marital status, disease incidence, and lethality. ${ }^{20}$

Table 6 Duration of symptoms prior to diagnosis of gastric cancer

\begin{tabular}{ll}
\hline Duration & Patients, $\mathbf{n}(\%)$ \\
\hline $0-1$ months & 0 \\
I-3 months & $\mathrm{I}(3)$ \\
$3-6$ months & $2(7)$ \\
$6-12$ months & $24(80)$ \\
I-2 years & $3(10)$ \\
\hline
\end{tabular}

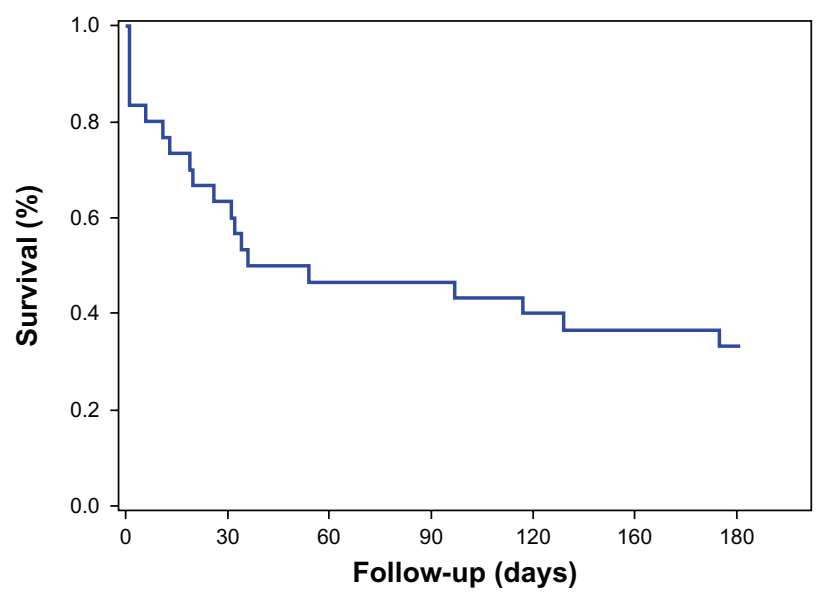

Figure I Survival at 6 months in patients under 30 years of age with gastric cancer. Note: Mean survival was 86.8 days ( $95 \%$ confidence interval: $59.3-140.3$ days).

Two general rules are clear now that Helicobacter pylori is accepted as the cause of atrophic gastritis and as a determining factor in the severity of the disease; that the severity of atrophic gastritis is related to cancer risk; and that atrophic gastritis is associated with other diseases such as duodenal ulcer, gastric ulcer, gastric carcinoma, and mucosa-associated lymphatic tissues ([MALT]-type gastric lymphoma). First, the pattern of gastritis is the greatest determinant of the disease; second, countries with a high prevalence of gastric cancer, such as Japan and Peru, have a low prevalence of duodenal ulcer. ${ }^{18,21,22}$

Isik et al concluded that young patients ( $<40$ years of age) with gastric cancer present with poorly differentiated adenocarcinoma and with more advanced and metastatic disease; the patient's health status, tumor localization, metastatic sites, and smoking status did not confer significant difference in disease state, which coincides with our series that reported a histology of poorly differentiated signet ring cell adenocarcinoma in $44 \%$ of our patient population. $^{23}$

Smith and Stabile, in a report on 350 patients, and with 30 patients $(9 \%)$ aged $<35$ years compared with those aged $>35$ years, found a greater incidence of invasion of adjacent organs ( $74 \%$ vs $29 \%$ ) and distant metastasis ( $81 \%$ vs $50 \%$ ) in patients younger than 35 years, as well as a reduced possibility of curative surgery ( $58 \%$ vs $17 \%$ ) and greater postsurgical mortality ( $22 \%$ vs $2 \%){ }^{24}$

Age as an adverse prognostic factor appears to be related to a greater degree with delay in diagnosis. Lai et al, in a series of 6954 patients divided into three groups by age (with $12.7 \%$ of patients aged $<40$ years, $66.7 \%$ aged $41-65$ years, and $20.6 \%>65$ years of age), concluded 
that patients $<40$ years of age exhibited significantly better survival than those in group two; multivariate analysis indicated that age was an independent prognostic factor. $^{25}$

To date, the reason for the occurrence of gastric cancer in young people remains inexplicable. In our series, we did not find that women predominantly have gastric cancer in this age group, as has been reported in other series in the literature. ${ }^{26}$ Conversely, in our study, $54 \%$ of the patients with gastric cancer were men.

Additionally, we found that despite aggressive surgical resection or neoadjuvancy, the outcomes from having gastric cancer continue to be invariably devastating. However, an attempt should be made to identify the subgroup of patients who can benefit from screening, and in whom early detection can be recommended. Attempting to identify the environmental factors that favor the progression or development of gastric cancer would also be ideal. We also recommend searching for a tumor marker to detect this disease in its earliest stages, given that therapies used for standard management of gastric cancer to date have not substantially improved the disease's prognosis. Prevention of the disease is optimal, as gastric cancer is truly difficult to control once it has been established.

\section{Conclusion}

To date, there has been a trend toward late diagnosis of gastric cancer in younger patients who present with symptoms. Physicians should account for the possibility of gastric cancer in patients with a familial history, or with symptoms of ulcer that do not improve under adequate medical management. With the diagnosis of an ulcer, panendoscopy should without exception be conducted to obtain a biopsy for early diagnosis, which can increase survival in young patients.

The clinical and pathological characteristics of gastric cancer in a series of patients included the following:

1. Similar proportion in both genders.

2. Histology of predominantly signet ring cells.

3. Prognosis depends on disease stage and not on the patient's age.

4. Delay in diagnosis of young patients leads to presentation at advanced disease stages and to young patients being candidates for palliative care.

5. Despite the lack of demonstrating a statistically significant $P$, a tendency could be demonstrated with an increase in sample size.
6. The patients studied were found to have progressed to advanced disease stages, when treatment was oriented toward palliative care of the disease.

\section{Disclosure}

The authors report no conflicts of interest in this work.

\section{References}

1. Jemal A, Siegel R, Xu J, Ward E. Cancer statistics, 2010. CA Cancer J Clin. 2010;60:277-300.

2. Parkin DM, Bray F, Ferlay J, Pisani P. Global Cancer Statistics, 2002. CA Cancer J Clin. 2005;55:74-108.

3. Compendium Histopathological Registry of Malignant Neoplasms in Mexico: Department of Epidemiology, Ministry of Health, 1997.

4. INEGI / Health Ministry. Deaths Database 2005. National Health Information. Mexico: SINAIS, 2010. Available at: www.sinais.salud. gob.m.

5. Buffart TE, Carvalho B, Hopmans E, et al. Gastric cancers in young and elderly patients show different genomic profiles. J Pathol. 2007;211: $45-51$.

6. Meyers WC, Damiano RJ, Postlethwaite RW, Rotolo FS Adenocarcinoma of the stomach: changing patterns over the last 4 decades. Ann Surg. 1987;205:1-8.

7. Nagini S. Carcinoma of the stomach: a review of epidemiology, pathogenesis, molecular genetics and chemoprevention. World $J$ Gastrointest Oncol. 2012;4(7):156-169.

8. Bedikian AY, Khankhanian N, Heilbrun LK, Bodey GP, Stroehlein JR, Valdivieso M. Gastric carcinoma in young adults. South Med J. 1979;72:654-656.

9. Bloss RS, Millar TA, Copeland EM 3rd. Carcinoma of the stomach in the young adult. Surg Gynecol Obstet. 1980;150:883-886.

10. Tso PL, Bringaze WL 3rd, Dauterive AH, Correa P, Cohn I Jr. Gastric carcinoma in the young. Cancer. 1987;59:1362-1365.

11. Shah MA, Kelsen DP. Gastric cancer: a primer on the epidemiology and biology of the disease and an overview of the medical management of advanced disease. J Natl Compr Canc Netw. 2010;8:437-447.

12. Chaytors RG. Gastric cancer in young people. Can Fam Physician. $1985 ; 31: 1335-1338$

13. Matley PJ, Dent DM, Madden MV, Price SK. Gastric carcinoma in young adults. Ann Surg. 1988;207:593-596.

14. Milne AN, Sitarz R, Carvalho R, Carneiro F, Offerhaus GJ. Early onset gastric cancer: on the road to unraveling gastric carcinogenesis. Curr Mol Med. 2007;7:15-28.

15. Park YK, Kim JC, Koh YS, et al. Early gastric carcinoma in young patients. Int Surg. 2006;91:316-319.

16. Dulak AM, Schumacher SE, van Lieshout J, et al. Gastrointestinal adenocarcinomas of the esophagus, stomach, and colon exhibit distinct patterns of genome instability and oncogenesis. Cancer Res. 2012;72:4383-4393.

17. Correa P, Shiao YH. Phenotypic and genotypic events in gastric carcinogenesis. Cancer Res. 1994;54(Suppl 7):1941s-1943s.

18. Rugge M, Leandro G, Farinati F, et al. Gastric epithelial dysplasia: how clinicopathologic background relates to management. Cancer. 1995;76: 376-382.

19. Siurala M, Sipponen P, Kekki M. Chronic gastritis: dynamic and clinical aspects. Scand J Gastroenterol Suppl. 1985;109:69-76.

20. Merrill RM, Sloan A, Anderson AE, Ryker K. Unstaged cancer in the United States: a population-based study [abstract]. BMC Cancer. 2011;11:402.

21. El-Zimaity HM. Gastric atrophy, diagnosing and staging. World $J$ Gastroenterol. 2006;12:5757-5762.

22. Dai YC, Tang ZP, Zhang YL. How to assess the severity of atrophic gastritis. World J Gastroenterol. 2011;17:1690-1693. 
23. Isik M, Caner S, Metin Seker M, et al. Gastric adenocarcinoma under the age of 40; more metastatic, less differentiated. $J$ BUON. 2011;16:253-256.

24. Smith BR, Stabile BE. Extreme aggressiveness and lethality of gastric adenocarcinoma in the very young. Arch Surg. 2009;144:506-510.
25. Lai JF, Kim S, Li C, et al. Clinicopathologic characteristics and prognosis for young gastric adenocarcinoma patients after curative resection. Ann Surg Arch. 2008;15:1464-1469.

26. Lai IR, Lee WJ, Chen CN, et al. Gastric cancer in the young. Hepatogastroenterology. 1997;44:1641-1645.

\section{Publish your work in this journal}

Cancer Management and Research is an international, peer-reviewed open access journal focusing on cancer research and the optimal use of preventative and integrated treatment interventions to achieve improved outcomes, enhanced survival and quality of life for the cancer patient. The journal welcomes original research, clinical \& epidemiological studies, reviews \& evaluations, guidelines, expert opinion \& commentary, case reports \& extended reports. The manuscript management system is completely online and includes a very quick and fair peerreview system, which is all easy to use. Visit http://www.dovepress.com/ testimonials.php to read real quotes from published authors. 